Julian Berry

is a Director of Marketing Planning Services Ltd, an agency

that uses audit, insight and unique software optimization tools to transform clients marketing planning.
Keywords: marketing budget optimisation, marketing resource allocation, econometrics, marketing eco-system

\section{The problem of optimization}

Julian Berry Marketing Planning Services Ltd, Trident House 46-48 Webber St, London, SE1 8QW, UK.

E-mail: info@marketing planningservices.com

\section{Opinion Piece}

\section{Time to take control? How to manage your own marketing resource allocation}

\author{
Julian Berry \\ Received (in revised form): 6th October 2014
}

\begin{abstract}
When it comes to how best to spend a marketing budget, marketers are probably not short of advice. Agencies, media planners, product managers, finance directors and channel managers can all try to influence their decisions and, in some cases, dogmatically state what is the 'right' approach. The question, however, is whether they are giving marketers the best impartial and objective advice - and how to know whether they are right or wrong.
\end{abstract}

Journal of Direct, Data and Digital Marketing Practice (2014) 16, 80-85. doi:10.1057/dddmp.2014.56

There is no doubt that optimizing marketing resource allocation is a minefield for most Chief Marketing Officers, and their planning support team. However, this does not need to be the case. This short paper describes the problem and explains an approach that any company concerned about how they are spending their budget, on above-the-line and below-the-line marketing, can adopt.

As far as we know, this approach is unique in that it utilizes two streams of historic marketing performance information when working out what the impact of marketing spend is on sales: both actual responses to campaigns that can be counted, such as source-coded orders or clicks, and models of how above-the-line and below-the-line channels impact sales at a macro level. By not discarding any information and using a pragmatic decision engine that forecasts into the future, we are proposing a solution that could put the marketer back in control.

\section{What we mean by 'marketing resource allocation'}

Marketing resource allocation is the process of deciding how best to divide and spread a marketing budget across multiple activities, each of which will impact on customer awareness and purchase behaviour. Larger business-to-consumer companies typically have between 100 and 1,000 campaign activities in their marketing budget. The problem they are trying solve is how to get the right spend in each row, to achieve their sales objectives most economically and to live within business constraints that may, for instance, require a minimum amount spent in a particular channel, 


\section{Ad spend forecast for f20bn in 2015}

\section{Five drivers of complexity}

or perhaps a maximum in another channel (such as outbound telephony where resources are finite).

Companies also need to allow for a range of semi-fixed costs, such as developing content, agency fees, database management, research, insight development and sponsorship. Although these cannot be included in a budget optimization model, they do effectively reduce the amount that can be spent. Optimal marketing resource allocation meets all these business objectives and constraints at the lowest possible cost.

\section{How big is the budgeting problem?}

Total UK advertising spend, which excludes 'invisible' areas such as telemarketing, email, mobile or salesforce, came to $£ 17.6$ bn in 2013, according to the Advertising Association. It is forecast to reach $£ 20$ bn by 2015. Among advertisers, the largest spender was BSkyB at $£ 264 \mathrm{~m}$ - the 100th on the list, Saga, still managed to spend £23.7 m (Figure 1).

But the budgeting problem is not just one of size; it is equally one of complexity. One could say that, when Lord Leverhulme (or it may in fact have been John Wanamaker) complained that 'half the money I spend on advertising is wasted, and the problem is that I do not know which half', he was having it comparatively easy.

In today's world, there are at least five main drivers of complexity:

- Rapid growth in the number of channels, with recent additions such as app and voucher marketing.

- Interactions between all the channels - it is no longer a question of just looking at how TV's 'halo effect' may impact other channels.

- How spend in one period impacts spend in subsequent periods, often known as the 'adstock effect'.

- Attribution for direct campaigns, when the immediate impact is often found to be primarily an increase in natural search volumes.

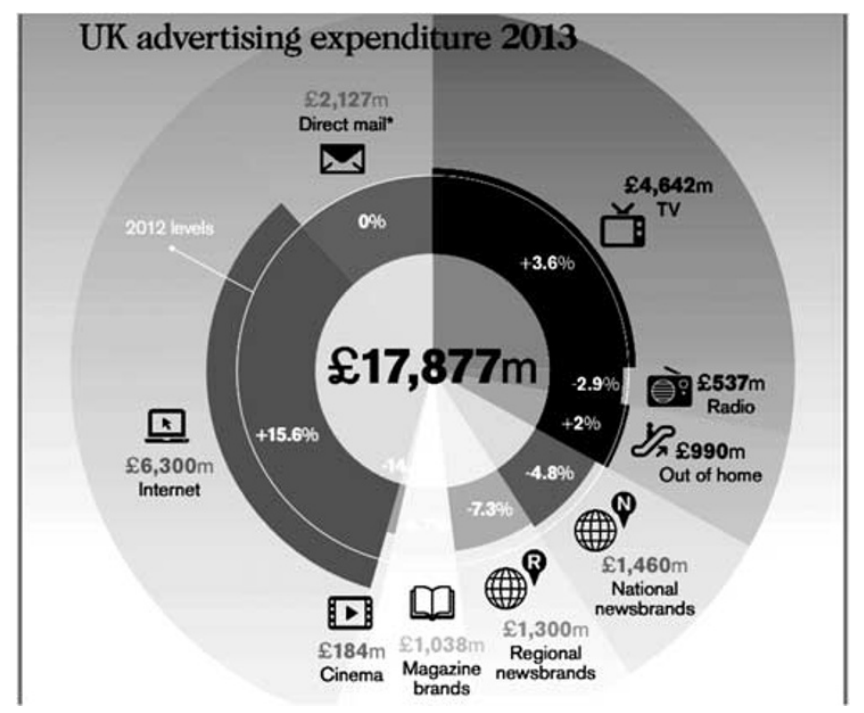

Figure 1: UK advertising expenditure in 2013

Source: Advertising Association 


\section{Three methods of estimation}

Decision Calculus

\section{Experimentation}

\section{Econometrics}

\section{Saturation curves in direct marketing}

- And, finally, the wild card - the impact of creativity. Some argue that variations in the impact of ads due to creative differences are greater than variations caused by different levels of spend.

No approach to marketing resource allocation is going to get all of this right, but we will chart an approach that at least tackles the top four of these areas.

\section{The right approach for estimating the impact of marketing on demand}

At the start of any marketing resource allocation process is the need to estimate the impact on demand of direct and non-direct advertising. (The impact of direct also needs to be unravelled as it can be masked by recipients using the internet to browse for purchase.) Two academics Sunil Gupta and Thomas J. Steenburgh - wrote a paper for the Harvard Business School in $2008^{1}$ in which they identified three main methods that are available to marketers for estimating the impact of non-direct advertising.

The first is what they call 'Decision Calculus' - in layman's terms, this is managerial insight where the cumulative experience of people in the business is used to estimate the impact of marketing.

Next is experimentation. This approach is often overlooked where time is of the essence and the luxury of embarking on a range of tests cannot be enjoyed. But in reality, where external conditions are relatively stable, experiments undoubtedly provide quality hard evidence. Different experimental techniques have been used, from picking matched cities and advertising differently in each, to using cable TV to field A/B tests.

The third and perhaps most popular technique is econometrics. The econometrician will take a time series of marketing spend history, usually at channel-by-week level, and use this to predict variations in sales for a product or brand. The more sophisticated models include changes in external market conditions, the behaviour of competitors and shifts in pricing. Econometrics needs significant variations in spend and sales over time - if all KPIs are flat, it is impossible to build a model.

Of these three, we favour econometrics, provided that it can take proper account of the impact of all off-line channels on natural search and web traffic. The approach we recommend builds a cluster of models to echo the multi-channel eco-system (see Figure 2).

For direct marketing, where a response is sought from targeted individuals, our approach is to develop saturation curves - these describe how, as more spend is put into a specific media or activity, its effectiveness declines. Every channel's performance will saturate as budgets increase. This saturation is effectively the cannibalization of media, that is caused by continuing to market to an individual who is already going to buy. After reviewing multiple clients' data across multiple sectors, we have seen that there are consistent and durable relationships within historic saturation curves. 


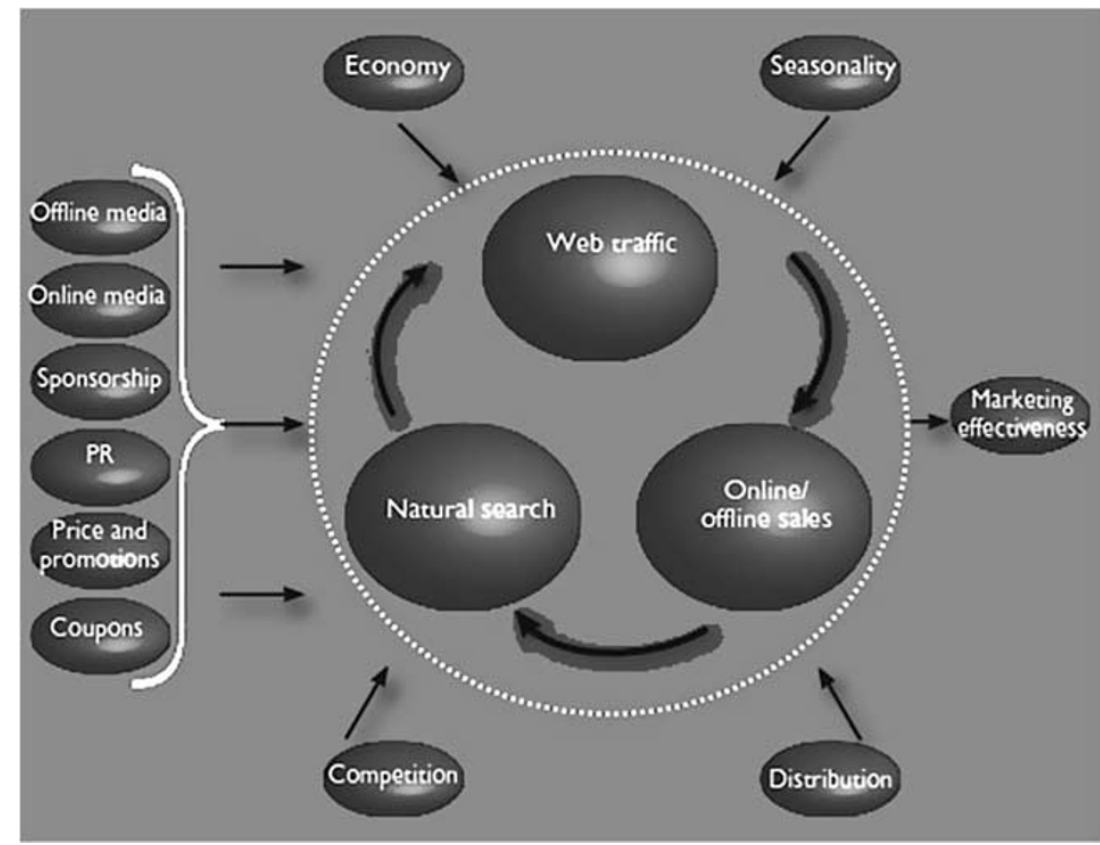

Figure 2: A typical marketing eco-system

Channel X YoY performance

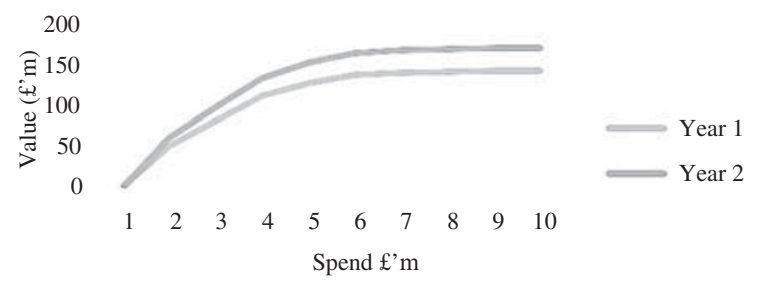

Figure 3: Value per unit spend declines as spend increases

Figure 3 illustrates how, as the spend increases, the incremental value decreases.

Figure 3 also shows that, while the two series are different, the overall relationship is similar. In this case, we can see that the return in the second year is 20 per cent better (across the board) than in the first year. This could possibly be telling us that, after the first year's learnings, processes are better and hence marketing is more efficient.

\section{A single model for optimization}

Targets and constraints

\section{Why an optimization model is needed}

Having achieved a means of estimating demand for both above-the-line and below-the-line advertising, these need to be combined into a single model in order to optimize marketing resource allocation looking forward. The model has to select the best combination of spend across all channels to understand how each unit of spend in any channel has the potential to impact the performance of all other channels.

The model also needs to accommodate specific business targets such as minimum levels of recruits, or sales of specific products. There will also be 


\section{Beyond known parameters}

\section{Multiple iterations of scenarios}

constraints, such as minimum spend in certain areas to reflect existing commitments, for example, to suppliers or partners. The model will need to be able to build forward scenarios, for example, for next year's budget, and show how the spend is to be allocated across the weeks and months in that period.

The model may need, within defined limits, to project spend that is outside the boundaries of any spend that has previously occurred. This means, in effect, extending curves beyond known parameters. And, finally, the model may need to work back from business targets - a scenario may need to answer a question of how much budget is needed to hit a specific sales target.

These requirements show how far we have moved outside the range of what human 'Decision Calculus' can normally be expected to achieve and into an area where optimization tools that can perform complex calculations are required. This is particularly necessary when the business wants multiple iterations of scenario projections until it has found an acceptable outcome.

Gupta and Steenburgh sensibly define the requirements of a good model as being:

- simple to understand;

- robust;

- easy to control;

- adaptive to change;

- complete;

- easy to communicate.

\section{Our approach}

We have developed a four-step approach:

- Import campaign performance history and build saturation curves (see Figure 4).
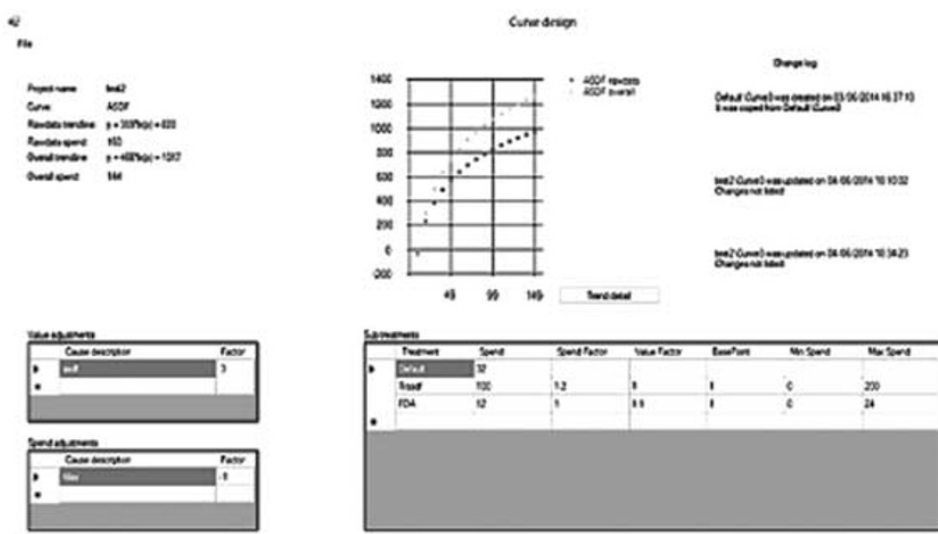

Figure 4: Importing campaign performance history and building saturation curves 


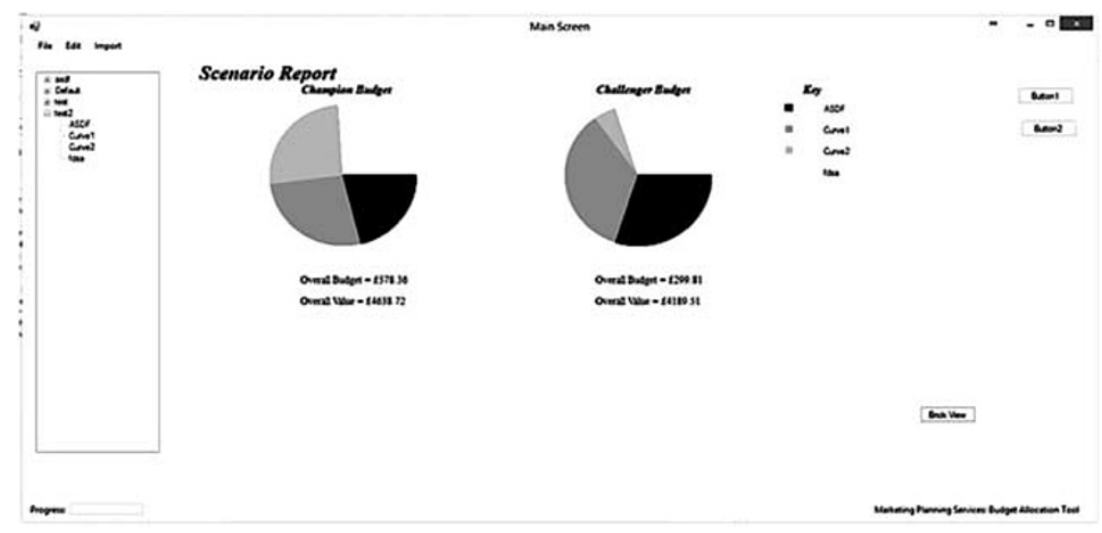

Figure 5: Comparing two scenario results with different spend allocations

- Build econometric models.

- Set up a budget allocation optimization model.

- Set parameters and run optimized resource allocation scenarios.

Where a company's knowledge and experience is most needed is in setting the parameters within which the scenarios can be run. This includes adjusting historic performance metrics to take account of new market conditions (what we earlier called Decision Calculus), fixing the overall budget, setting maxima and minima for specific areas of spend, and setting targets for, for example, sales or customer recruitment.

That done, a good budget allocation optimization model will take

Budget allocation scenarios

Objective and credible account of the campaign histories, saturation curves and econometric effects, in conjunction with your parameters, to provide an optimized and detailed budget allocation plan (see Figure 5).

\section{The benefits}

Taking control of your marketing budget allocation has a significant number of benefits:

- Objectivity (no risk of recommendations being biased by supplier selfinterest).

- Credibility (with all input marketing metrics and outputs being auditable, you will get fewer challenges to the scale of the marketing budget).

- Efficiency (once set up, you can run new budget scenarios in minutes and respond to changing market and competitor environments).

- Return on investment (you will be using science to optimize the return on your marketing investments, unhampered by vested interests).

\section{Reference}

1. Gupta, S. and Steenburgh, T.J. (2008) 'Allocating marketing resources', http://hbswk.hbs.edu/ item/5868.html, accessed 12 March 2008. 